\title{
MEAN CENTRAL DISTANCE-CENTRAL DISTANCE INEQUALITIES
}

\section{Jia Jin Wen, Shan He Wu, Jun Yuan and Tian Yong Han}

Abstract. By means of the analysis, convex geometry, computer and majorization theories, in the centered 2 -surround system $S^{(2)}\{P, \Gamma, l\}$, we establish the following mean central distancecentral distance inequalities:

$$
\frac{\exp \left(\frac{1}{|\Gamma|} \oint_{\Gamma} \log \bar{r}_{P}\right)}{\exp \left(\frac{1}{|\Gamma|} \oint_{\Gamma} \log r_{P}\right)} \geqslant \frac{1}{2}\left[\sec \frac{l \pi}{|\Gamma|}+\cot \frac{l \pi}{|\Gamma|} \log \left(\tan \frac{l \pi}{|\Gamma|}+\sec \frac{l \pi}{|\Gamma|}\right)\right]
$$

and

$$
\frac{\left(\frac{1}{|\Gamma|} \oint_{\Gamma} \bar{r}_{P}^{2}\right)^{1 / 2}}{\frac{1}{|\Gamma|} \oint_{\Gamma} r_{P}} \geqslant \frac{1}{2}\left[\sec \frac{l \pi}{|\Gamma|}+\cot \frac{l \pi}{|\Gamma|} \log \left(\tan \frac{l \pi}{|\Gamma|}+\sec \frac{l \pi}{|\Gamma|}\right)\right] \text { when } 0<\angle A P A_{+} \leqslant \tau,
$$

where $\tau=2.49342812654089 \ldots$, and $\tau / 2$ is the unique real root of the following equation:

$$
\frac{\mathrm{d}^{2}[\sec \theta+\cot \theta \log (\tan \theta+\sec \theta)]}{\mathrm{d} \theta^{2}}=0, \theta \in\left(0, \frac{\pi}{2}\right) .
$$

We also demonstrate the applications of our results, and obtain the $N$-mean central distance central distance inequality and the mean central distance-central distance-limit inequality.

Mathematics subject classification (2010): 26D15, 26E60, 51K05, 52A40.

Keywords and phrases: Isoperimetric inequality, $p$-mean, surround system, mean central distance, Schur-convex function.

\section{REFERENCES}

[1] J. J. Wen And C. B. GAO, Geometric inequalities involving the central distance of the centered 2-surround system, Acta. Math. Sinica., 51 (4) (2008), 815-832, (in Chinese).

[2] C. B. GaO AND J. J. Wen, Theory of surround system and associated inequalities, Comput. Math. Appl., 63 (12) (2012), 1621-1640.

[3] C. B. GAO AND J. J. Wen, Theories and inequalities on the satellite system, ISRN Math. Anal., 2011, Article ID 909261, 22 pages.

[4] J. J. WEN, J. YUAN AND S. H. WU, Isoperimetric inequalities in surround system and space science, J. Inequal. Appl., 2016, 74 (2016), 28 pages.

[5] J. J. WEN AND W. L. WANG, The inequalities involving generalized interpolation polynomial, Comput. Math. Appl., 56 (4) (2008), 1045-1058.

[6] J. J. Wen AND S. S. Cheng, Closed balls for interpolating quasi-polynomials, Comput. Appl. Math., 30 (3) (2011), 545-570.

[7] P. S. Bullen, P. S. Mitrinović And P. M. Vasić, Means and their inequalities, Reidel: Dordrecht/Boston/Lancaster/Toyyo, 1988.

[8] J. J. WEN, J. YUAN AND S. F. YUAN, An optimal version of an inequality involving the third symmetric means, Proc. Indian Acad. Sci. Math. Sci., 118 (4) (2008), 505-516.

[9] C. B. GAO AND J. J. WEN, A dimensionality reduction principle on the optimization of function, J. Math. Inequal., 7 (3) (2013), 357-375. 
[10] J. J. WEN AND W. L. WANG, The optimization for the inequalities of power means, J. Inequal. Appl., 2006, Article ID 46782, 25 pages.

[11] J. J. WEN AND W. L. WANG, Chebyshev type inequalities involving permanents and their applications, Linear Algebra Appl., 422 (1) (2007), 295-303.

[12] J. J. WEN, T. Y. HAN AND S. S. CHENG, Inequalities involving Dresher variance mean, J. Inequal. Appl., 2013, 366 (2013), 29 pages.

[13] D. KING-HELE, Theory of satellite orbits in an atmosphere, Butterworths, London, 1964.

[14] F. Della Pietra And N. Gavitone, The Relative isoperimetric inequality: the anisotropic case, J. Convex Anal., 20 (1) (2013), 157-180.

[15] F. R. K. Chung And P. TETALI, Isoperimetric inequalities for Cartesian products of graphs, Combin. Probab. Comput. 7 (2) (1998), 141-148.

[16] J. J. WEN AND B. J. ZHOU, The isoperimetric inequality in $\mathbb{R}^{3}$, J. Chengdu University (Natural Science), 25 (4) (2006), 241-246, (in Chinese).

[17] A. W. Marshall And I. Olkin, Inequalities: Theory of majorization and its applications, Academic Press, New York, 1979.

[18] S. H. Wu, On the weighted generalization of the Hermite-Hadamard inequality and its applications, Rocky Mountain J. Math., 39 (5) (2009), 1741-1749.

[19] J. J. WEN, J. E. PEČARIĆ AND Y. H. TiAn, Weak monotonicity and Chebyshev type inequality, Math. Inequal. Appl., 18 (1) (2015), 217-231.

[20] J. J. WEN AND Z. H. ZHANG, Jensen type inequalities involving homogeneous polynomials, J. Inequal. Appl., 2010, Article ID 850215, 21 pages.

[21] J. J. WEn, Y. HuAng AND S. S. CHEnG, Theory of $\phi$-Jensen variance and its applications in higher education, J. Inequal. Appl., 2015, 270 (2015), 40 pages.

[22] J. J. WEN, C. B. GAO AND W. L. WANG, Inequalities of J-P-S-F type, J. Math. Inequal., 7 (2) (2013), 213-225.

[23] J. E. PeČArić, F. Proschan And Y. L. Tong, Convex functions, Academic Press, Boston, MA, 1992.

[24] J. J. WEN, The inequalities involving Jensen functions, J. Sys. Sci. Math. Sci., 27 (2) (2007), 208-218, (in Chinese).

[25] D. L. REN, Topics in integral geometry, World Scientific Publishing Co., River Edge, NJ, 1994. 